\title{
Inventário de Práticas Docentes que Favorecem a Criatividade no Ensino Superior
}

\author{
Eunice M. L. Soriano de Alencar ${ }^{12}$ \\ Universidade Católica de Brasilia \\ Denise de Soura Fleith \\ Universidade de Brasília
}

\begin{abstract}
Resumo
Este estudo teve como objetivo construir e validar um instrumento que permitisse avaliar a percepção de estudantes universitários quanto à extensão em que seus professores vinham apresentando comportamentos e implementando práticas docentes que favorecem o desenvolvimento e a expressão da criatividade do aluno. O instrumento denominado Inventário de Práticas Docentes era composto de 37 itens relativos a diversas dimensões da criatividade. Este instrumento foi aplicado em 1068 estudantes de universidades pública e privada. Foi efetuada uma análise fatorial e 4 fatores foram gerados: Incentivo a Novas Idéias, Clima para Expressão de Idéias, Avaliação e Metodologia de Ensino e Interesse pela Aprendizagem do Aluno. Os coeficientes a de fidedignidade obtidos para os fatores foram superiores a 0,72 . Os resultados indicam que o inventário discrimina distintas dimensões do comportamento docente que são relevantes para o desenvolvimento da criatividade, constituindo-se em um instrumento útil para fins de pesquisa e diagnóstico de práticas docentes.

Palavras-chave: Professor; práticas docentes; criatividade.
\end{abstract}

Inventory of Educational Practices that Favor Creativity in Higher Education Level

\begin{abstract}
The purpose of this study was to construct and validate an instrument that assessed university students' perception with respect to what extent their teachers had presented behaviors and implemented educational practices that favoured the development and expression of students' creativity. The instrument was named Inventory of Educational Practices and consisted of 37 itens related to distinct dimensions of creativity. This instrument was administered to 1068 students from public and private universities. A factorial analysis was conducted and four factors were generated: Incentive to New Ideas, Climate for the Expression of Ideas, Evaluation and Methodology of Teaching, and Interest for the Student's Learning. The alpha coefficients of reliability for all factors were above .72. The results indicated that the inventory discriminates distinct dimensions of teacher behavior that are relevant to the development of creativity, being an useful instrument for researching and diagnosing educational practices.

Keywords: Teacher; educational practices; creativity.
\end{abstract}

Há um reconhecimento crescente de que é necessário preparar o aluno para o presente cenário, onde a capacidade de pensar e resolver novos problemas ocupa um lugar central. Iniciativas que vêm sendo tomadas por governos de distintos países no sentido de promover um debate e implementar uma política educacional que assegure o desenvolvimento das habilidades criativas dos estudantes foram, por exemplo, apontadas por autores diversos, como Craft (1998), Cohen (1997), Tan (2001), Strom e Strom (2002). Paralelamente a este reconhecimento, observa-se, entretanto, que falhas têm sido constatadas no que diz respeito à promoção da criatividade nos distintos níveis de ensino, ressaltando vários autores (Alencar, 1995a, 1995b, 2001, 2002a; Cole, Sugioka \& Yamagata-Lynch, 1999; Furman, 1998; MacKinnon, 1978; Sternberg, 1991) que não é raro a escola desencorajar a expressão da criatividade e mesmo puni-la.

\footnotetext{
${ }^{1}$ Este trabalho contou com o apoio do CNPq (Proc. 522138/95-0).

${ }^{2}$ Endereço para correspondência: Programa de Mestrado em Educação, Universidade Católica de Brasília, SGAN 916 Módulo B Asa Norte, 70790 170, Brasília, DF. Fone: (61) 3405550 (r. 155), Fax: (61) 3405550. E-mail: ealencar@pos.ucb.br
}

No que diz respeito ao ensino superior, críticas foram feitas por Paulovich (1993), nos Estados Unidos, Tolliver (1985) no Canadá, Cropley (1997), na Alemanha e Castanho (2000) e Rosas (1985), no Brasil, pelas possibilidades limitadas e/ ou falta de incentivo à criatividade.

Paulovich (1993), por exemplo, critica a educação universitária, por não encorajar o pensamento criativo e independente. Segundo esta autora, "estudantes ansiosos por notas são forçados a memorizar e regurgitar um volume incrível de fatos em um ritmo que impede mesmo o mais entusiasta de refletir sobre o material ensinado ou ser intelectualmente estimulado" (p. 565). Também Tolliver (1985), no Canadá, aponta um conjunto de práticas educacionais, no ensino universitário, que inibem a expressão da criatividade e que punem os alunos mais criativos. Considera ele que, em função do que ocorre comumente na universidade, "os educadores podem estar encorajando os estudantes a cometer atrocidades intelectuais para sobreviver" (p. 35). De forma similar, Cropley (1997), na Alemanha, salienta que as escolas e universidades estão 
produzindo um grande número de graduados, porém a maioria deles treinados simplesmente para aplicar o já conhecido de maneira convencional. Lembra Cropley a grande necessidade de uma educação que encoraje a criatividade.

No Brasil, o pouco espaço para o desenvolvimento da criatividade nos cursos universitários tem sido apontado por autores diversos, como Alencar (1995b, 1996, 1997), Castanho (2000) e Rosas (1985). Neste sentido, Rosas ressalta que:

é no terceiro grau onde menos se fala e pensa em criatividade. Excetuando-se as escolas e/ou departamentos de artes, parece que os demais professores têm muito mais o que fazer do que se preocupar com a imaginação, fantasia e criação. (p. 122)

De forma similar, Castanho considera que:

podemos afirmar que nossas faculdades são, no geral, pouco ou nada criativas. Desenvolver a criatividade parece ser um objetivo tão simples e é uma das características mais raras de se encontrar na maioria de nossos jovens, educados para a atitude conformista e homogênea que os sistemas escolares os condenam. (p. 77)

Também Alencar (2002a) aponta a prevalência de uma cultura de aprendizagem que estabelece limites muito abaixo das possibilidades praticamente ilimitadas do potencial para criar do ser humano. Em vários de seus estudos, Alencar (1994, 1995a, 1995b, 1997) pôde constatar a prática de se exigir do aluno a reprodução de conhecimentos e a memorização, requerendo dos mesmos conhecimentos muitas vezes obsoletos. Isto foi observado, por exemplo, em uma análise de conteúdos de provas utilizadas em distintos níveis de ensino e de livros textos adotados em escolas do país. Em nível universitário, em estudo sobre a percepção de estudantes a respeito da extensão em que diferentes aspectos que favorecem a expressão da criatividade eram estimulados por seus professores, observaram-se condições que refletiam baixo incentivo ao desenvolvimento das habilidades criativas do aluno.

Por outro lado, Fleith (2000) salienta que há professores conscientes das características de sala de aula que estimulam a criatividade dos alunos. Entretanto, a transferência para a prática parece ser intuitiva. A informação limitada de como cultivar as habilidades criativas em sala de aula é explicada, por esta autora, pela ausência de conteúdos na área de criatividade na formação do professor.

Apesar de os autores anteriormente citados terem chamado a atenção para a necessidade de se promover melhores condições ao desenvolvimento da criatividade nos cursos universitários, observa-se escassez de estudos empíricos avaliando a extensão em que comportamentos docentes, que favorecem a expressão da criatividade, têm sido apresentados por professores universitários e em que freqüência. Nota-se também uma carência de instrumentos padronizados que visem a avaliar a extensão em que professores vêm apresentando comportamentos e práticas docentes que favorecem o desenvolvimento e expressão das habilidades criativas de seus estudantes. Os poucos inventários descritos na literatura consultada, como o utilizado por Furman (1998) e por Soh (2000), não foram construídos visando especificamente a sua utilização entre estudantes universitários. O primeiro foi aplicado em professores e alunos do ensino fundamental e o segundo validado em uma amostra de apenas 117 professores que lecionavam no ensino fundamento e médio. Com vistas a preencher esta lacuna no que concerne ao ensino universitário, foi desenvolvido o presente estudo. Este teve como objetivo construir e validar um instrumento que permitisse avaliar a percepção de estudantes universitários quanto à extensão em que seus professores vinham apresentando comportamentos e implementando práticas docentes que favorecem o desenvolvimento e expressão da criatividade do aluno. É relevante informar que foram também construídas mais duas versões do referido instrumento para serem respondidos por professores universitários. Estas serão ainda submetidas a estudo de validação.

\section{Método}

\section{Etapas da Construção do Inventário de Práticas Docentes}

Fez-se inicialmente uma revisão de literatura da teoria e pesquisa sobre criatividade em contextos educacionais, detendo-se especialmente em estudos sobre criatividade na sala de aula universitária. Aproveitaram-se também os 19 itens de um instrumento construído pela primeira autora (Alencar, 1995) para avaliar o grau de incentivo a diferentes aspectos da criatividade por parte de professores universitários, tendo este instrumento sido utilizado em vários estudos com amostras tanto de estudantes de graduação quanto de pós-graduação (Alencar, 1995b, 1997, 2002b). Este instrumento anterior foi construído para ser respondido por estudantes considerando os professores universitários de modo geral, ao invés de um professor específico. Isto gerou críticas por parte de respondentes que ressaltaram diferenças entre seus professores no que diz respeito aos comportamentos referentes aos aspectos que estavam sendo investigados.

Outros itens foram, a seguir, elaborados com base especialmente em resultados de uma pesquisa realizada por Alencar (2000) a respeito do professor universitário facilitador e inibidor da criatividade, na qual duas questões abertas foram utilizadas para levantar o perfil desses professores 
junto a pós-graduandos. Na primeira, solicitava-se ao estudante para selecionar, dentre os seus professores, aquele que melhores condições ofereceu para o desenvolvimento e expressão das habilidades criativas de seus estudantes e a seguir, apresentar uma descrição o mais detalhada possível de comportamentos típicos deste professor em sala de aula, da maneira com trata os estudantes tanto em sala como fora dela, dos métodos de ensino mais usados pelo professor selecionado, do seu grau de preparação e interesse em relação à matéria sob sua responsabilidade no programa e outros dados que considerasse relevantes a respeito do professor. $\mathrm{Na}$ segunda questão, solicitam-se os mesmos dados, porém com relação ao professor inibidor. Constatou-se que, na descrição do professor, técnicas instrucionais, grau de preparação do professor, qualidade da relação professoraluno, interesse pela matéria e pela aprendizagem do aluno e traços de personalidade do docente foram os aspectos mais apontados.

Desenvolveu-se, então, o Inventário de Práticas Docentes, com 37 itens, elaborando-se três versões: uma a ser respondida pelo professor considerando seus comportamentos típicos em sala de aula; uma segunda versão a ser respondida pelo professor na perspectiva de seus alunos, ou seja, considerando como seriam as respostas de seus alunos ao avaliarem os seus comportamentos docentes em sala de aula; e uma terceira versão, com os mesmos itens, porém, a ser completada pelos estudantes avaliando o referido professor.

Cada um dos itens é respondido em uma escala de cinco pontos, que varia de "discordo plenamente" até "concordo plenamente". Complementam o instrumento uma página inicial, com instruções de como respondê-lo, o levantamento de dados biográficos dos respondentes, e uma página final contendo espaço para comentários e as observações que o respondente julgar pertinentes.

Após esta etapa, realizou-se um estudo piloto com o objetivo de analisar semanticamente os itens construídos, a fim de se garantir a sua compreensão, evitando ambigüidade e formulações pouco apropriadas. Para tal, o instrumento foi aplicado em oito turmas (sete em universidade pública e uma em universidade particular), solicitando-se aos respondentes que indicassem possíveis itens confusos ou ambíguos e que sugerissem formulações para os mesmos. Cento e trinta e dois alunos e sete professores responderam ao instrumento.

Imediatamente após esta etapa, procedeu-se à reformulação de dois itens e acréscimo de um item. Deste procedimento, resultaram 38 itens que compuseram, inicialmente, o instrumento.

\section{Participantes e Procedimentos}

Para validação estatística do instrumento, foi feita uma aplicação do mesmo em uma amostra de 1068 estudantes universitários, cujas características são apresentadas a seguir.
Seiscentos e doze $(57,3 \%)$ estudantes eram do gênero feminino e 449 (42\%) do gênero masculino. Sete estudantes $(0,7 \%)$ não responderam esta questão. Dos 1068 estudantes, $599(56,1 \%)$ eram provenientes de cursos na área de Ciências, enquanto $467(43,7 \%)$ eram alunos de cursos na área de Humanidades. Dois estudantes $(0,2 \%)$ não informaram o curso que freqüentavam. Seiscentos e oito estudantes $(56,9 \%)$ estavam matriculados em instituições particulares de ensino superior do Distrito Federal e 459 (43\%) freqüentavam uma instituição pública. Um estudante não respondeu à questão $(0,1 \%)$. A maioria dos estudantes $(n=731)$, participantes do estudo, estavam cursando a primeira metade do curso $(68,4 \%)$. Trezentos e vinte e três estudantes $(30,2 \%)$ estavam na segunda metade do curso. Quatorze alunos $(1,3 \%)$ não informaram quantos semestres haviam cursado. A idade média dos estudantes foi 23,97 anos, variando de 16 a 68 anos.

As autoras do presente estudo estabeleceram contatos com coordenadores e/ou professores de distintos cursos no sentido de solicitar a sua colaboração no projeto. Também os auxiliares de pesquisa colaboraram na identificação e contato com docentes universitários que estariam disponíveis a participar do estudo. Foi, ainda, solicitado ao professor que marcasse um horário durante uma de suas aulas para que os seus alunos pudessem responder ao instrumento. A aplicação dos instrumentos foi realizada por bolsistas de Iniciação Científica e alunos de graduação, matriculados em disciplina de pesquisa, treinados para esta tarefa. Foi assegurado aos participantes do estudo o caráter confidencial de suas respostas.

\section{Análise de Dados}

Dos instrumentos aplicados, 807 foram utilizados para fins de validação, não sendo os demais aproveitados, uma vez que os sujeitos deixaram de responder a um ou mais itens, não chegando a completá-lo. Para estabelecer a validade de construto do instrumento foi verificada sua estrutura interna por meio de análise fatorial. Utilizando-se o pacote estatístico SPSS 8.0, realizou-se uma análise dos eixos (Principal Axis Factoring), com rotação oblíqua (oblimin), antecedida por análise exploratória dos dados, com vista a verificar a normalidade das distribuições e os pressupostos da análise fatorial.

\section{Resultados}

Cinco fatores foram extraídos com base no critério de Kaiser (Gable \& Wolf, 1993), em que o eigenvalue do fator deve ser igual ou maior que 1. A solução de 5 fatores explicou $49,9 \%$ da variância comum. Entretanto, um dos fatores foi descartado por incluir apenas um item. Este item (item 15: Dá tempo aos alunos para pensarem e desenvolverem idéias novas) não foi alocado 
em nenhum dos fatores remanescentes e, por isso, foi, também, eliminado. Além disso, integraram os fatores apenas os itens com carga fatorial igual ou maior que 0,30 . A versão final da escala inclui, portanto, 37 itens. Os quatro fatores apontados pela análise serão descritos a seguir.

\section{Fator 1 - Incentivo a Novas Idéias}

O fator 1, denominado Incentivo a Novas Idéias, inclui 14 itens relativos à estimulação das habilidades cognitivas e características afetivas associadas à criatividade dos alunos. O eigenvalue deste fator foi 15,72, que explica $40,14 \%$ da variância comum. $O$ índice de consistência interna $(\alpha)$ foi de 0,93 . Os itens componentes deste fator com as respectivas cargas fatoriais são apresentados na Tabela 1.

\section{Fator 2 - Climapara Expressão de Idéias}

Este fator inclui 6 itens que dizem respeito à postura de respeito e aceitação por parte do professor acerca das idéias apresentadas pelos alunos (veja Tabela 2). O eigenvalue deste fator foi 1,89 , que explica $3,75 \%$ da variância comum. $\mathrm{O}$ índice de consistência interna $(\alpha)$ obtido foi 0,72 .

\section{Fator 3 - Avaliação e Metodologia de Ensino}

O fator 3, denominado Avaliação e Metodologia de Ensino, engloba 5 itens relativos a práticas de ensino favoráveis ao desenvolvimento da expressão criativa (veja Tabela 3). O eigenvalue deste fator foi 1,54 , que explica $2,56 \%$ da variância comum. O índice de consistência interna $(\alpha)$ foi de 0,85 .

Fator 4 - Interesse pela Aprendizagem do Aluno

O fator 4, denominado Interesse pela Aprendizagem do Aluno, inclui 12 itens envolvendo estratégias e recursos de ensino que motivam o aluno a aprender de forma criativa (veja Tabela 4). O eigenvalue deste fator foi 1,26, que explica 2,06\% $\mathrm{da}$ variância comum. $\mathrm{O}$ índice de consistência interna $(\alpha)$ obtido foi de 0,72 .

Tabela 1

Cargas Fatoriais dos Itens que Integram o Fator 1 (Incentivo a Novas Idéias)

\begin{tabular}{llc}
\hline Item & Conteúdo & Carga \\
\hline 1 & Cultiva nos alunos o gosto pela descoberta e busca de novos conhecimentos & 0,54 \\
2 & Faz perguntas desafiadoras que motivem os alunos a pensar e raciocinar & 0,72 \\
3 & Estimula os alunos a analisarem diferentes aspectos de um problema & 0,85 \\
4 & Estimula a iniciativa dos alunos & 0,62 \\
5 & Estimula o aluno a pensar idéías novas relacionadas ao conteúdo da disciplina & 0,66 \\
6 & Promove a autoconfiança dos alunos & 0,48 \\
7 & Estimula a curiosidade dos alunos através das tarefas propostas & 0,56 \\
8 & Incentiva a independência dos alunos & 0,52 \\
9 & Desenvolve nos alunos habilidades de análise crítica & 0,71 \\
10 & Leva o aluno a perceber e conhecer pontos de vistas divergentes sobre o mesmo problema ou & 0,78 \\
& tema de estudo & 0,53 \\
12 & Incentiva os alunos a fazerem questões relativas aos temas estudados & 0,45 \\
18 & Apresenta vários aspectos de uma questão que está sendo estudada & 0,33 \\
20 & Promove o debate com estímulo à participação de todos os alunos & 0,36 \\
21 & Faz perguntas, buscando conexões com assuntos abordados & \\
\hline
\end{tabular}

Nota. Eigenvalue $=15,72$. Número de itens $=14$.

Tabela 2

Cargas Fatoriais dos Itens que Integram o Fator 2 (Clima para Expressão de Idéias)

\begin{tabular}{lll}
\hline Item & Conteúdo & Carga \\
\hline 11 & Valoriza as idéias originais dos alunos & 0,39 \\
14 & Cria um ambiente de respeito e aceitação pelas idéias dos alunos & 0,61 \\
16 & Dá chances aos alunos para discordarem de seus pontos de vista & 0,57 \\
34 & Escuta com atenção as intervenções dos alunos & 0,60 \\
35 & Não está atento aos interesses dos alunos & 0,55 \\
37 & Tem senso de humor em sala de aula & 0,41
\end{tabular}

Nota. Eigenvalue $=1,89$. Número de itens $=6$. 
Tabela 3

Cargas Fatoriais dos Itens que Integram o Fator 3 (Avaliação e Metodologia de Ensino)

\begin{tabular}{lll}
\hline Item & Conteúdo & Carga \\
\hline 13 & Preocupa-se apenas com o conteúdo informativo & 0,47 \\
17 & Utiliza formas de avaliação que exigem do aluno apenas a reprodução & 0,70 \\
& do conteúdo dado em classe ou contido nos livros-texto & 0,64 \\
19 & Utiliza sempre a mesma metodologia de ensino & 0,37 \\
27 & Faz uso de formas diversificadas de avaliação & 0,50 \\
30 & Oferece aos alunos poucas opções de escolha com relação aos & \\
& trabalhos a serem desenvolvidos & \\
\hline
\end{tabular}

Nota. Eigenvalue $=1,54$. Número de itens $=5$.

Tabela 4

Cargas Fatoriais dos Itens que Integram o Fator 4 (Interesse pela Aprendizagem do Aluno)

\begin{tabular}{lll}
\hline Item & Conteúdo & Carga \\
\hline 22 & Utiliza exemplos para ilustrar o que está sendo abordado em classe & 0,50 \\
23 & Está disposto a elucidar dúvidas dos alunos & 0,48 \\
24 & Proporciona ampla bibliografia relativa aos tópicos abordados & 0,35 \\
25 & Desperta o interesse dos alunos pelo conteúdo ministrado & 0,41 \\
26 & Tem disponibilidade para atender os alunos fora de sala de aula & 0,36 \\
28 & Apresenta situações-problema a serem solucionadas pelos alunos & 0,39 \\
29 & Expõe o conteúdo de uma maneira didática & 0,57 \\
31 & Dá feedback construtivo aos alunos & 0,51 \\
32 & Oferece informações importantes e interessantes relativas ao conteúdo da disciplina & 0,58 \\
33 & Tem entusiasmo pela disciplina que leciona & 0,46 \\
36 & Tem expectativas positivas com relação ao desempenho dos alunos & 0,44 \\
38 & Apresenta conteúdo atualizado & 0,53 \\
\hline
\end{tabular}

Nota. Eigenvalue $=1,26$. Número de itens $=12$.

\section{Discussão}

Os resultados obtidos sugerem que o Inventário de Práticas Docentes constitui-se em um instrumento útil para fins de pesquisa e diagnóstico de condutas docentes que favorecem o desenvolvimento e expressão das habilidades criativas de estudantes universitários. Os quatro fatores resultantes da análise fatorial dizem respeito a distintos atributos do professor, a dinâmica de sua prática docente e interesse pelo aluno e por sua aprendizagem. Estes são elementos presentes nas estratégias sugeridas por distintos especialistas, como Torrance $(1970,1987,1995)$, Cropley (1997, Cropley \& Urban, 2000), Renzulli (1992), Fleith (2001), Alencar $(2001,2002 a)$ para se promover a criatividade em sala de aula. Um grau aceitável de consistência interna foi observado nos distintos fatores e ainda uma correlação expressiva item-total.

Além de sua aplicação para pesquisa, o instrumento pode também ser utilizado para dar aos professores feedback de suas práticas docentes tais quais percebidas pelos alunos. $\mathrm{O}$ mesmo pode ainda ser aplicado para complementar dados coletados via observação do professor em sala de aula e/ ou entrevista, ajudando a eliminar vieses e contribuindo para a validação do estudo (Gall, Borg \& Gall, 1996).

Nota-se que, no presente estudo, o foco foi o professor universitário em sala de aula. Este, sem dúvida, é de fundamental importância no processo de ajudar o aluno a desenvolver o seu potencial e adquirir competências desejáveis para a sua realização pessoal e profissional, como apontado por inúmeros autores, como Alencar (2001), Cropley (1997), Furman (1998), Sternberg (1991), Tan (2001), dentre outros. Entretanto, é relevante lembrar que há outros elementos que contribuem para o que ocorre em sala de aula, com influência no comportamento do professor que ministra uma disciplina. Tanto a natureza do conteúdo a ser ministrado quanto o número de alunos em sala, o grau de motivação e esforço dos mesmos, por exemplo, têm influência na dinâmica em sala de aula. $\mathrm{O}$ conhecimento que se tem sobre o impacto de distintas variáveis no desenvolvimento e expressão da criatividade no contexto educacional é ainda limitado. 
Ressalta-se ainda que criatividade é um fenômeno complexo e plurideterminado. Inúmeras características do indivíduo e do ambiente contribuem para a sua maior ou menor expressão e desenvolvimento. Elementos dos distintos ambientes onde o indivíduo se acha inserido, como família e escola, além de fatores da sociedade, têm influência na expressão da criatividade. Ademais, como ressaltado por Sternberg e Lubart (1995), o tipo de ambiente que facilita o desenvolvimento e realização do potencial criativo depende de muitos fatores, como por exemplo, dos interesses do indivíduo, seu nível de potencial criativo, background de conhecimentos, disponibilidade de tempo para se dedicar uma área específica, sendo complexa a interação entre os múltiplos elementos que têm influência na expressão da criatividade.

Esperamos que o instrumento aqui apresentado possa contribuir para ampliar o conhecimento sobre este fenômeno fascinante que é a criatividade e especialmente o seu desenvolvimento no contexto educacional. Que os resultados obtidos com o seu uso contribuam para mudanças que são hoje necessárias, como ressaltado por Castanho (2000): “as escolas precisam mudar. Os tempos atuais exigem uma cultura ampla e criativa, que permeia toda a ação na sociedade, capilarizando-se por todas as instituições" (p. 76).

\section{Referências}

Alencar, E. M. L. S. (1994). Creativity in the Brazilian educational context: Two decades of research. Gifted and Talented International, 9, 4-7.

Alencar, E. M. L. S. (1995a). Challenges to the development of creative talent. Giffed and Talented International, 10, 5-8.

Alencar, E. M. L. S. (1995b). Developing creativity at the university level. European Journal for High Ability, 6, 82-90.

Alencar, E. M. L. S. (1996). University students' evaluation of their own level of creativity and their teachers' and colleagues' level of creativity. Gifted Education International, 11, 128-130.

Alencar, E. M. L. S. (1997). O estímulo à criatividade no contexto universitário. Psicologia Escolar e Educacional, 1, 29-37.

Alencar, E. M. L. S. (2000). O perfil do professor facilitador e do professor inibidor da criatividade segundo estudantes de pós-graduação. Boletim da Academia Paulista de Psicologia, 19, 84-95.

Alencar, E. M. L. S. (2001). Criatividade e a educação do superdotado. Petrópolis, RJ: Vozes.

Alencar, E. M. L. S. (2002a). Mastering creativity for education in the 21st century. Proceedings of the Biennial World Conference of the World Council for Gifted and Talented Children (pp. 13-21). Northridge, CA: World Council for Gifted and Talented Children.

Alencar, E. M. L. S. (2002b). O estímulo à criatividade em programas de pósgraduação segundo seus estudantes. Psicologia: Reflexão e Crítica, 15, 63-69.
Castanho, M. E. L. M. (2000). A criatividade na sala de aula universitária. Em I. P. Veiga \& M. E. L. M. Castanho (Orgs.), Pedagogia universitária. A aula em foco (pp. 75-89). São Paulo: Papirus.

Cohen, D. (1997). Singapore wants its universities to encourage more creativity. The Chronicle of Higher Education, September, 71-72.

Cole, D. G., Sugioka, H. L. \& Yamagata-Lynch, L. C. (1999). Supportive classroom environments for creativity in higher education. Journal of Creative Behavior, 33, 277-292.

Craft, A. (1998). Educator perspectives on creativity: An English study. Journal of Creative Behavior, 32, 244-256.

Cropley, A. J. (1997). Fostering creativity in the classroom: General principles. Em M. A. Runco (Org.), The creativity research book (pp. 83-114). Cresskill, NJ: Hampton Press.

Cropley, A. J. \& Urban, K. K. (2000). Programs and strategies for nurturing creativity. Em K. A. Heller, F. J. Monks, R. J. Sternberg \& R. F. Subotnik (Orgs.), International handbook of giftedness and talent (pp. 485-498). Kidlington, Oxford: Elsevier Science.

Fleith, D. S. (2000). Teacher and student perceptions of creativity in the classroom environment. Roeper Review, 22, 148-153.

Fleith, D. S. (2001). Criatividade: Novos conceitos e idéias. Aplicabilidade à educação. Cadernos de Educação Especial, 17, 55-61.

Furman, A. (1998). Teacher and pupil characteristics in the perception of the creativity of classroom climate. The Journal of Creative Behavior, 32, 258-277.

Gable, R. K. \& Wolf, M. B. (1993). Instrument development in the affective domain $\left(2^{\mathrm{a}}\right.$ ed.). Boston: Kluwer Academic.

Gall, M. D., Borg, W. R. \& Gall, J. P. (1996). Educational research (6a ed.). White Plains, NY: Longman.

MacKinnon, D. W. (1978). In search of human effectiveness: Identifying and developing creativity. Buffalo, NY: The Creative Education Foundation.

Paulovich, A. (1993). Creativity and graduate education. Molecular Biology of the Cell, 4, 565-568.

Renzulli, J. S. (1992). A general theory for the development of creative productivity through the pursuit od ideal acts of learning. Gifted Child Quarterly, 36, 170182.

Rosas, A. (1985). Universidade e criatividade. Anais do VII Seminário Nacional sobre Superdotados, 121-124.

Soh, K. C. (2000). Indexing creativity fostering teacher behavior: A preliminary validation study. Journal of Creative Behavior, 34, 118-132.

Sternberg, R. J. (1991, julho). A theory of creativity. Trabalho apresentado no XIV ISPA Colloquium, Braga, Portugal.

Sternberg, R. J. \& Lubart, T. I. (1995). Defjing the crowd: Cultivating creativity in a culture of conformity. New York: The Free Press.

Strom, R. D. \& Strom, P. S. (2002). Changing the rules: Education for creative thinking. Journal of Creative Behavior, 36, 183-200.

Tan, A. G. (2001). Singaporean teachers' perceptions of activities useful for fostering creativity. Journal of Creative Behavior, 35, 131-148.

Tolliver, J. M. (1985). Creativity at university. Giffed Education International, 3, 32-35.

Torrance, E. P. (1970). Encouraging creativity in the classroom. Dubuque, IA: William C. Brown.

Torrance, E. P. (1987). Teaching for creativity. Em S. G. Isaksen (Org.), Frontiers of creativity researcb: Beyond the basics (pp. 189-215). Buffalo, NY: Bearly.

Torrance, E. P. (1995). Why fly? A philosophy of creativity. Norwood, NJ: Ablex.

Sobre os autores

Eunice Maria Lima Soriano de Alencar é PhD pela University of Purdue nos Estados Unidos e Professora da Universidade Católica de Brasília. É pesquisadora do CNPq.

Denise de Souza Fleith é PhD pelo National Research Center on the Gifted and Talented na University of Connecticut, Estados Unidos. É representante do Brasil no Conselho Mundial para Crianças Superdotadas e Talentosas. É pesquisadora do CNPq. 